Z. klin. Chem. u. klin. Biochem.

8. Jg., S. 35-37, Januar 1970

\title{
Untersuchung der Fructose-Phosphat-Aldolase bei experimenteller Leberschädigung an Ratten
}

\author{
III. Leberscbädigung mit Tetracblorkoblenstoff
}

Von A. L. Dikow und D. Hadjiolov

Aus der Biocbemischen Abteilung und der Abteilung für Experimentalkanzerogenese des Onkologischen Forscbungsinstituts (Direktor: Prof. Dr. N. Antchew), SofialBulgarien

(Eingegangen am 12. August 1969)

\begin{abstract}
Das Isoenzymmuster der Serumaldolase wird bei Ratten nach Intoxikation mit Tetrachlorkohlcnstoff untersucht. 6, 12 und 24 Stdn. nach Versuchsbeginn beobachtet man eine starke Erhöhung der Serumaldolaseaktivität, die von einer Verminderung der Aktivität des Enzyms in der Leber begleitet wird. Im Isoenzymmuster der Serumaldolase (Substrat Fructose-1-phosphat bzw. Fructose-1,6-diphosphat) erscheinen bei den Versuchstieren gleichzeitig neue Isoenzymfraktionen vom Typ Aldolase B und in den späteren Stadien der Intoxikation - auch vom Typ Aldolase C. Die Erhöhung der Serumaldolase kann mit der Entwicklung der zentrolobulären Zellnekrosen im Parenchym sowie mit der Schädigung auch von anderen Organen infolge der Intoxikation erklärt werden.
\end{abstract}

\section{Studies on fructose phosphate aldolase in experimental liver damage in rats. III, Liver damage by carbon tetracbloride}

The isoenzyme pattern of serum aldolase was studied in rats following poisoning with carbon tetrachloride. At 6,12 and 24 hours after administration of the carbon tetrachloride, there was a marked increase in serum aldolase activity accompanied by a decrease in the activity of the enzyme in the liver. New isoenzyme fractions of type B aldolase appeared together in the isoenzyme pattern of the serum aldolase (substrates, fructose-1-phosphate or fructose-1,6-diphosphate) in the experimental animals; fractions of type $C$ aldolase also appeared in later stages of the toxicosis. The increase in serum aldolase is attributed to the centrolobular cell necrosis in the parenchyma and to damage to other organs caused by the toxicosis.

Bei unseren früheren Untersuchungen über Parenchymschädigungen der Leber mit 4-Dimethylaminoazobenzol und Diäthylnitrosamin beobachteten wir im Serum einen wesentlichen Anstieg der Fructose-Phosphat-Aldolase sowie Veränderungen in ihrem Isoenzymmuster $(1,2)$. Die biochemischen und histochemischen Untersuchungen der Enzymaktivität zeigten, daß der Enzymaustritt in das Blut sowohl auf die Parenchym-Zell-Schädigung als auch auf die Zellnekrosen zurückgeführt werden kann. Um den Schädigungsgrad der Leber für die Veränderungen der Serumaldolase besser beurteilen zu können, untersủchten wir die akute Intoxikation mit Tetrachlorkohlenstoff, bei welcher sich in kurzen Zeitabschnitten (32 Stdn.) deutliche zentrale und subtotale Nekrosen am Leberparenchym bilden und eine diffuse fettige Degeneration auftritt (3).

\section{Material und Methode}

Die Versuche wurden an männlichen Albinoratten von 140-160 g Gewicht durchgeführt, welche intraperitoneal $0,1 \mathrm{ml}$ Tetrachlorkohlenstoff/100 g Gewicht injiziert erhielten. In der 6., 12. und 24. Std. wurden Gruppen von je 10 Tieren durch die A. femoralis entblutet. Im Blutserum bestimmten wir die Gesamt-Aldolaseaktivität mit dem Aldolase-UV-Test, Fa. Boehringer, Mannheim. Lebergewebe von Versuchstieren sowie unbehandelten Kontrollen homogenisierten wir bei $0^{\circ}$ und zentrifugierten 1 Std. bei $160000 \mathrm{~g}$ und $0^{\circ}$. Im klaren Uberstand bestimmten wir das Gesamteiweiß und die Aldolaseaktivität gegenüber Fructose-1,6-diphosphat (FDP) und Fructose-1-phosphat (FMP) nach früher beschriebenem Verfahren (4). Die Isoenzyme der Aldolase wurden elektrophoretisch auf 0,6proz. Agarosegel mit Tris/EDTA/ Borsäure-Puffer $\mathrm{pH} 8,9$ getrennt (4); ihre Detektion erfolgte nach früher vorgeschlagener Methode (5). Dieses Material untersuchten wir histologisch nach Routineverfahren.

\section{Ergebnisse und Diskussion}

Die beobachteten morphologischen Leberveränderungen zeigten eine für die akute Intoxikation mit Tetrachlorkohlenstoff typische Fettdystrophie, gefolgt von hydropischer Degeneration und zentrolobulären Zellnekrosen. Der histochemische Nachweis der Aldolase in der Leber der Versuchtsiere zeigte eine deutliche Verminderung der Enzymaktivität im Cytoplasma der Leberzellen mit groben Fỏrmazanablagerungen vorwiegend in der Zellperipherie (Abb. 1). Die Ergebnisse aus den Untersuchungen der Gesamt-Aldolaseaktivität sind auf Tabelle 1 dargestellt.

Aus der Tabelle ist zu ersehen, $\mathrm{da} ß$ die Serumaldolaseaktivität $z$ wischen der 6 . und 24 . Stunde stark ansteigt

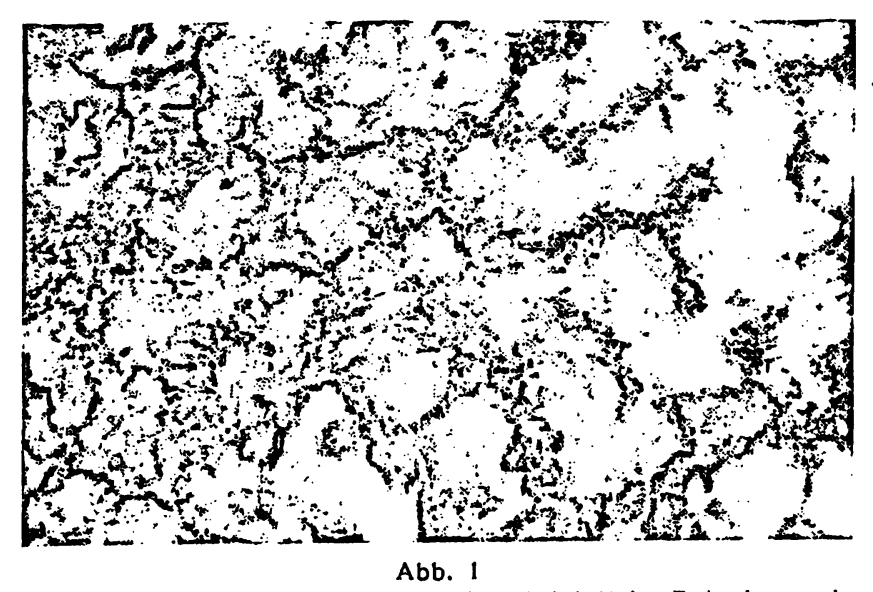

Ausgeprägte Verminderung der Aldolaseaktivität im Zytoplasma der Leberzellen in der 12. Std. nach Injektion von Tetrachlorkohlenstoff. Grobe Formazanablagerungen vorwiegend in der Zellperipherie. (Substrat: Fructose-1,6-diphosphat, ohne Kernfärbung) Vergr. 400 fach 
Tab. 1

Gesamt-Aldolaseaktivität im Serum von Versuchs- und Kontrollratten in $\mathrm{mU} / \mathrm{ml}$ und in der Leber gegenüber FDP und FMP in $\mu$ Mol FDP und FMP/mg Gewebseiwei $\beta$. Min. bei $37^{\circ}$ sowie das Verhältnis gegenüber den beiden Substraten (FDP/F 10 Bestimmungen

\begin{tabular}{lrccc}
\hline Versuchstiere & Serum & \multicolumn{3}{c}{ Leber } \\
& & FDP & FMP & FDP/FMP \\
\hline 6. Std. & 357,80 & 0,58 & 0,25 & 2,32 \\
12. Std. & 442,20 & 0,64 & 0,27 & 2,37 \\
24. Std. & 734,60 & 0,35 & 0,11 & 3,18 \\
Kontrolltiere & 56,46 & 0,93 & 0,83 & $1,12$. \\
\hline
\end{tabular}

und $15 \mathrm{mal}$ höhere Werte erreicht als bei den Kontrolltieren. Dagegen sinkt im selben Zeitabschnitt die Aldolaseaktivität der Leber. Diese Aktivitätsverminderung äußert sich besonders gegenüber Fructose-6-phosphat, weshalb das Verhältnis der Aktivität gegenüber beiden Substraten ansteigt. Das Isoenzymmuster der Serumaldolase ist auf Abbildung 2 dargestellt. Unter Anwendung des Substrats Fructose-1,6-diphosphat wird im Serum der Kontrolltiere (Abb. 2 a) eine intensive, ano-

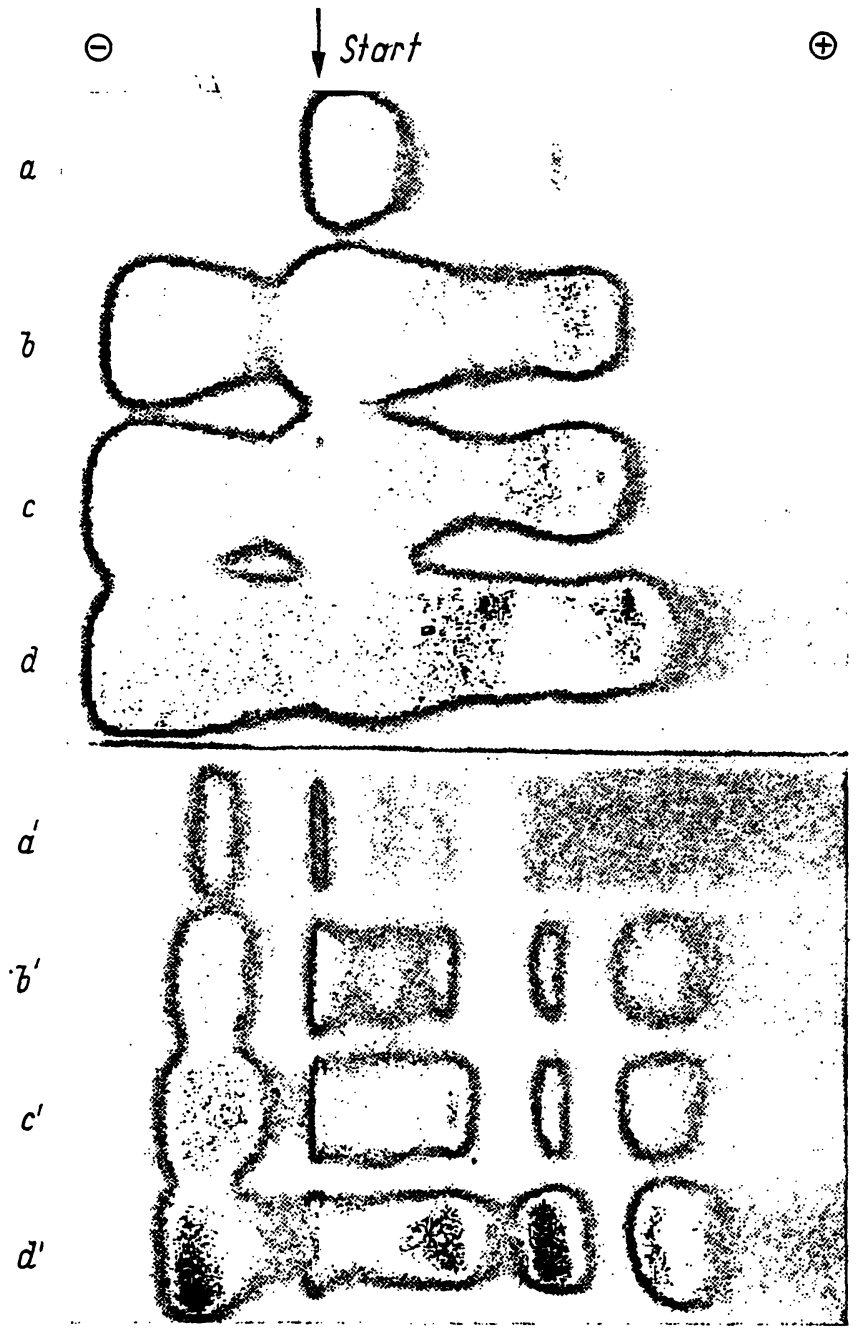

Abb. 2

Isoenzymmuster der Serumaldolase bei Ratten a, b, c, d) Substrat: Fructose-1,6-diphosphat $\left.a^{\prime}, b^{\prime}, c^{\prime}, d^{\prime}\right)$ Substrat: Fructose-1-phosphat $\left.a, a^{\prime}\right)$ bei einem Kontrolltier

$\left.b, b^{\prime}\right)$ in der 6. Std., $c, c^{\prime}$ ) in der 12. Std. und $d, d^{\prime}$ ) in der 24. Std. nach Injektion von Tetrachlorkohlenstoff disch bei der Startlinie liegende Fraktion nachgewiesen, sowie eine schwächere Fraktion am anodischen Ende des Zymogramms. Bei den Versuchstieren (Abb. 2 b, c, d) werden in der 6 . und besonders deutlich in der 12 . und 24. Stunde wesentliche Veränderungen im Isoenzymmuster der Serumaldolase festgestellt. Die anodisch bei der Startlinie liegende Fraktion fließt mit einigen neuen, sehr intensiven' Fraktionen zusammen, indem sich ein intensiver Fleck auf der anodischen Seite des Zymogramms bildet. Im anodischen Teil des Zymogramms treten zwei sehr intensive Isoenzymfraktionen vom Typ Leber Aldolase B hervor, die ebenfalls zusammenfließen.

Bei Anwendung des Substrats Fructose-6-phosphat beobachteten wir im Isoenzymmuster der Kontrolltiere (Abb. 2a') nur eine kathodische Fraktion vom Typ Aldolase B. Bei den Versuchstieren (Abb. $2 b^{\prime}, c^{\prime}, d^{\prime}$ ) wird diese kathodische Fraktion breiter und erhöht ihre Intensität mehrfach. Im anodischen Teil des Zymogramms erscheinen außerdem vier neue, deutlich voneinander

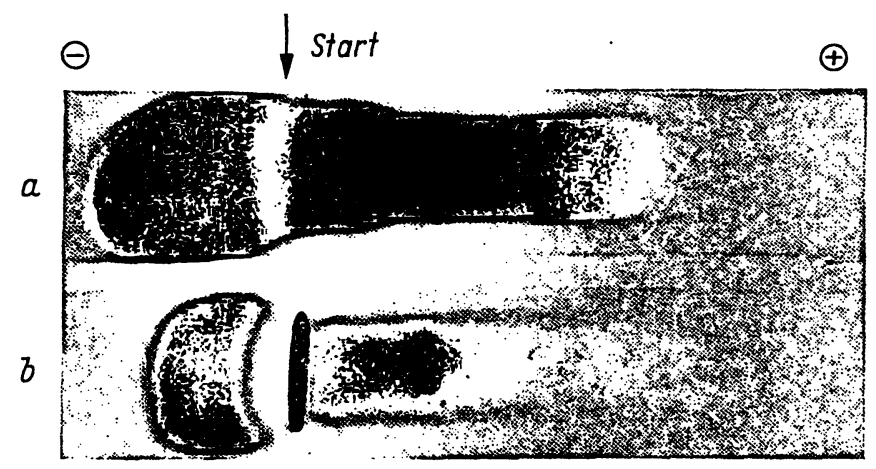

Abb. 3

Isoenzymmuster der Aldolase in normaler Rattenleber

a) Substrat: Fructose-1,6-diphosphat b) Substrat: Fructose-1-phosphat

abgesonderte intensive Fraktionen, die besonders gut in der 24. Stunde nach Versuchsbeginn zu beobachten sind. Auf Abbildung 3 ist das Isoenzymmuster der Aldolase in einer normalen Leber dargestellt, um die Herkunft der obenerwähnten Veränderungen im Isoenzymmuster der Serumaldolase zeigen zu können.

Wie manche Verfasser annehmen (6), besteht bei der Intoxikation mit Tetrachlorkohlenstoff eine gewisse Korrelation zwischen der Entwicklung der Lebernekrosen und dem Niveau der Enzyme. Während der stärksten Veränderungen im Leberparenchym bemerken JUDAH und Mitarbeiter (7), daß das Niveau der im Blut auftretenden mitochondrialen Enzyme nicht höher als $2-4 \%$ im Vergleich zu der gesamten Leber ist. Bei unseren Versuchen sinkt die Aldolaseaktivität in der Leber um die 24. Stunde stark, gleichzeitig mit der Entwicklung der ausgeprägten zentrolobulären Zellnekrosen im Parenchym. Dies wird von einem beträchtlichen Anstieg der Enzymaktivität im Serum begleitet. $\mathrm{Da}$ unter den Versuchsbedingungen eine Aktivierung oder eine erhöhte Synthese des Enzyms ausgeschlossen 
werden kann, muß der erwāhnte Anstieg der Aktivitāt im Serum lediglich mit dem Enzymaustritt aus der Leber in das Blut begründet werden.

Bei der Gegenüberstellung der Isoenzymmuster der Serumaldolase bei Versuchstieren mit dem Isoenzymmuster der normalen Leber ist vor allem ein Anstieg der Intensitāt der Fraktionen vom Typ Leber Aldolase B zu beobachten. Ein Teil der anodischen Fraktionen im Serum der Versuchstiere unter Anwendung des Substrats Fructose-6-phosphat fehlen in der normalen Leber. Dies weist darauf hin, $\mathrm{da} B$ in den fortgeschrittenen Stadien der Intoxikation ein Teil der erhöhten Serumaldolaseaktivităt auf die Schädigung auch ron anderen Organen zurückzuführen ist.

\section{Literatur}

1. Drkow, A. L. und D. Hadjrolov, diese Z. 7, 160 (1969). 2. Drkow, A. L. und D. Hadjrozov, diese Z. 7, 556 (1969). -

3. Rath, T. W. und R. Nilius, Exper. Path. 1, 195 (1967). -

4. Dikow, A. L. und V. Genowa, diese Z. 7, 155 (1969). -
5. Dikow, A. L., diese Z. 6, 386 (1968). - 6. ReEs, K. R. und K. P. Sinha, J. Path. Bact. 80, 297 (1960). - 7. Judaf, J. D., K. Arsezd und A. E. M. McLeas, Ciba Foundation Symposium on Cellular Injury, S. 193, Verlag J. A. Churchill, London (1964).

Dr. med. Angel L. Dikow Ruhr-Universität Lchrstuhl Biochemie 4630 Bochum-Querenburg Postfach 2148 